Liver, Pancreas and Biliary Tract

\title{
Epidemiology, clinical features and diagnostic work-up of cystic neoplasms of the pancreas: Interim analysis of the prospective PANCY survey
}

\author{
Raffaele Pezzillia ${ }^{a, *, 1}$, Elisabetta Buscarini ${ }^{\mathrm{b}, 1}$, Tommaso Pollini ${ }^{\mathrm{c}}$, Deborah Bonamini ${ }^{\mathrm{c}}$, \\ Giovanni Marchegiani ${ }^{\mathrm{c}}$, Stefano Crippa ${ }^{\mathrm{d}}$, Giulio Belfiori ${ }^{\mathrm{d}}$, Cosimo Sperti ${ }^{\mathrm{e}}$, Lucia Moletta ${ }^{\mathrm{e}}$, \\ Gioia Pozza ${ }^{\mathrm{e}}$, Germana De Nucci ${ }^{\mathrm{f}}$, Giampiero Manes ${ }^{\mathrm{f}}$, Enzo D. Mandelli ${ }^{\mathrm{f}}$, Riccardo Casadei ${ }^{\mathrm{g}}$, \\ Claudio Ricci ${ }^{\mathrm{g}}$, Saverio Alicante ${ }^{\mathrm{b}}$, Claudia Vattiato ${ }^{\mathrm{b}}$, Silvia Carrara ${ }^{\mathrm{h}}$, Milena Di Leo ${ }^{\mathrm{h}}$, Carlo Fabbri ${ }^{\mathrm{i}}$, \\ Silvia Giovanelli ${ }^{j}$, Luca Barresi ${ }^{\mathrm{k}}$, Matteo Tacelli ${ }^{\mathrm{k}}$, Vincenzo G. Mirante ${ }^{1}$, Rita Conigliaro ${ }^{1}$,
} Filippo Antonini ${ }^{\mathrm{m}}$, Giampiero Macarri ${ }^{\mathrm{m}}$, Luca Frulloni $^{\mathrm{n}}$, Giulia De Marchi ${ }^{\mathrm{n}}$, Romano Sassatelli ${ }^{\mathrm{o}}$, Paolo Cecinato $^{\circ}$, Giovanna Del Vecchio Blanco ${ }^{\mathrm{p}}$, Andrea Galli ${ }^{\mathrm{q}}$, Angelo Pezzullo ${ }^{\mathrm{r}}$, Alberto Fantin ${ }^{\mathrm{s}}$, Massimo Graffeo ${ }^{t}$, Mauro Frego ${ }^{u}$, Domenico Stillittano ${ }^{v}$, Fabio Monicaw ${ }^{w}$, Bastianello Germanà ${ }^{x}$, Gabriele Capurso $^{\mathrm{y}, 3}{ }^{\text {, Mariano }}$ Quartini ${ }^{\mathrm{z}}$, Luigi Veneroni ${ }^{\mathrm{A}}$, Renato Cannizzaro ${ }^{\mathrm{B}, 2}$, Massimo Falconi ${ }^{\mathrm{d}, 2}$

a Department of Gastroenterology, San Carlo Hospital, Potenza, Italy

b Gastroenterology and Endoscopy Unit, Maggiore Hospital, Crema, Italy

${ }^{\text {c }}$ Pancreas Institute, Verona University, Verona, Italy

d Pancreatic Surgery Unit, Pancreas Translational E' Clinical Research Centre, IRCCS San Raffaele Scientific Institute, Vita-Salute University, Milan, Italy

e Department of Surgical, Oncological and Gastroenterological Sciences, University of Padua, Padua, Italy

${ }^{\mathrm{f}}$ Gastroenterology and Endoscopy Unit, Rhodense Hospital, Milan, Italy

' Surgical Department, Polyclinic of Sant'Orsola, University of Bologna, Bologna, Italy

${ }^{\mathrm{h}}$ Humanitas Clinical and Research Center, IRCCS, Digestive Endoscopy Unit, Division Of Gastroenterology, Milan, Italy

${ }^{\mathrm{i}}$ Unit of Gastroenterology and Digestive Endoscopy, Forlì-Cesena, Italy

j Gastroenterology and Interventional Endoscopy Unit, Maggiore Hospital, Bologna, Italy

${ }^{\mathrm{k}}$ Endoscopy Service, Department of Diagnostic and Therapeutic Services, IRCCS-ISMETT (Mediterranean Institute for Transplantation and Highly Specialized Therapies), Palermo, Italy

${ }^{1}$ Gastroenterology and Endoscopy Unit, Baggiovara Hospital, University Hospital, Modena, Italy

$\mathrm{m}$ Gastroenterology and Digestive Endoscopy Unit, Augusto Murri Hospital, Polytechnic University of Marche, Fermo, Italy

${ }^{\mathrm{n}}$ Gastroenterology, Department of Medicine, The Pancreas Institute, University of Verona Hospital Trust, Verona, Italy

${ }^{\circ}$ IRCCS Hospital, Reggio Emilia, Italy

$\mathrm{P}$ Unit of Gastroenterology, Department of Medicine, Tor Vergata University, Rome, Italy

${ }^{\mathrm{q}}$ Gastroenterology Research Unit, Department of Experimental and Clinical Biomedical Sciences, Florence, Italy

${ }^{\mathrm{r}}$ Department of Anesthesiological, Surgical and Emergency Sciences, University of Naples, Naples, Italy

${ }^{s}$ Gastroenterology Unit, Padua, Italy

${ }^{\mathrm{t}}$ Department of Internal Medicine, Gastroenterology and Endoscopy, Poliambulanza Hospital, Brescia, Italy

u Surgical Department, Ospedali Riuniti, Padua, Italy

${ }^{v}$ Digestive Endoscopy Unit, Desio Hospital, Milan, Italy

${ }^{\mathrm{w}}$ Gastroenterology and Digestive Endoscopy, Cattinara Hospital, Cattinara, Trieste, Italy

x Gastroenterology Unit, San Martino Hospital, Belluno, Italy

y Digestive and Liver Disease Unit, S. Andrea Hospital, Rome, Italy

${ }^{2}$ Gastroenterology Unit, Santa Maria Hospital, Terni, Italy

A Surgical Department, Infermi Hospital, Rimini, Italy

${ }^{\mathrm{B}}$ Oncological Center, Aviano-Pordenone, Italy

\section{A R T I C L E I N F O}

\section{Article history:}

Received 23 November 2019

Accepted 9 February 2020

Available online 29 February 2020

\section{A B S T R A C T}

Introduction: A prospective survey to evaluate the diagnostic workup of cystic pancreatic neoplasms (CPNs) according to the Italian guidelines.

Methods: An online data sheet was built.

\footnotetext{
* Corresponding author at: Dipartimento di Gastroenterologia, Ospedale San Carlo, Via P. Petrone, 85100 Potenza, Italy.

E-mail address: raffaele.pezzilli@gmail.com (R. Pezzilli).

1 Raffaele Pezzilli and Elisabetta Buscarini share the first authorship.

2 Renato Cannizzaro and Massimo Falconi share the senior authorship.

3 Current address: Pancreaticobiliary and EUS Unit, Pancreas Center, IRCCS San Raffaele Scientific Institute, Vita-Salute University, Milan, Italy.
} 
Keywords:

Biomarkers

Cystic neoplasm

Cytology

Endosonography

Epidemiology

Magnetic resonance imaging

Multidetector computed tomography

Pancreatic cyst
Results: Fifteen of the 1385 patients (1.1\%) had non cystic neoplastic lesions. Forty percent (518/1295) had at least one 1st degree relative affected by a solid tumor of the digestive and extra-digestive organs. Symptoms/signs associated with the cystic lesion were present in $24.5 \%$ of the patients. The cysts were localized in the head of the pancreas in 38.5\% of patients. Of the 2370 examinations (1.7 examinations per patient) which were carried out for the diagnosis, magnetic resonance imaging was performed as a single test in $48.4 \%$ of patients and in combination with endoscopic ultrasound in $27 \%$ of the cases. Of the 1370 patients having CPNs, $89.9 \%$ had an intraductal papillary mucinous neoplasm (IPMN) (70.1\% a branch duct IPMN, 6.2\% a mixed type IPMN and 4.6\% a main duct IPMN), $12.7 \%$ had a serous cystadenoma, $2.8 \%$ a mucinous cystadenoma, $1.5 \%$ a non-functioning cystic neuroendocrine neoplasm, $0.7 \%$ a solid-pseudopapillary cystic neoplasm, $0.3 \%$ a cystic adenocarcinoma, and $1.2 \%$ an undetermined cystic neoplasm. Seventy-eight (5.7\%) patients were operated upon after the initial work-up.

Conclusions: This prospective study offers a reliable real-life picture of the diagnostic work-up CPN.

(c) 2020 Editrice Gastroenterologica Italiana S.r.l. Published by Elsevier Ltd. All rights reserved.

\section{Introduction}

The use of imaging in recent decades has evidenced an increased incidence of cystic neoplasms of the pancreas (CPNs) [1,2]. However, information regarding CPNs mostly derive from retrospective studies. In fact, in a recent meta-analysis, of the 17 studies included, only 3 were prospective [3]. Thus, there is a clear lack of prospective studies, particularly in the European context.

CPNs are mostly detected incidentally when non-invasive abdominal imaging is performed for unrelated indications; of them, mucinous neoplasms are the most common lesions, although they rarely present an indication for surgery. Clinicians are faced with a high, and ever-increasing, prevalence of CPNs due to population ageing and management difficulties, with the inherent risks of over- or misuse of diagnostic tests, entailing unnecessary risk and discomfort for patients and wasted resources for the health care system. In fact, despite the increased awareness of these lesions, their natural history is still partially unclear and, thus, optimal management is still under debate.

In 2014, the Italian Association of Hospital Gastroenterologists and Endoscopists (AIGO) and the Italian Association for the Study of the Pancreas (AISP) released consensus guidelines for the diagnostic work-up and follow-up of cystic pancreatic neoplasms [4] and the quality assessment [5] found them [6,7] methodologically sound. The AIGO and the AISP made a commitment to validate the guidelines with a prospective data collection to evaluate whether these recommendations were improving patient diagnostics and management [4]. Thus, a prospective survey was designed to evaluate the real-life diagnostic workup and management of pancreatic cystic neoplasms, and the applicability and potential inadequacies of the Italian guidelines regarding CPNs. This paper presents the interim analysis of the main features of the patients enrolled, particularly focused on diagnostic burden and workup at initial presentation.

\section{Ethics}

The study obtained the approval of the Ethical Committee of the Crema Hospital on December 11, 2014, protocol number 375. Written, informed consent was obtained from each patient included in the study. The study protocol conforms to the ethical guidelines of the 1975 Declaration of Helsinki as reflected in a priori approval by the institution's human research committee

\section{Methods}

The present study was named PANCY (PANcreatic CYsts). A dedicated online data sheet was built, also providing a quality check of the data entered. Any inaccuracy in the data sheet was evaluated by the coordinating center.

The inclusion criteria were the following: (1) $\geq 18$ years of age, (2) a therapeutic opportunity was suitable at the time of diagnosis or during the follow up, (3) having non-inflammatory pancreatic single or multiple cysts and (4) signing the form agreeing to participate to the study. In addition, Italian guidelines recommend that a sampling of CPNs is indicated when a previous diagnostic modality has shown cyst with "suspicious" features other than an enhancing solid component or when the other diagnostic modalities fail to obtain a definite diagnosis, or in cases of advanced malignant CPNs when chemotherapy is considered. Finally, the same guidelines recommend that the sampling of CPNs has to be performed using an endoscopic ultrasound (EUS) examination because there are no data supporting the role of percutaneous guided sampling of cysts [4]. Complications of EUS interventional approach were defined according the criteria previously reported [8] and severity of pancreatitis was graded according to the modified Atlanta criteria [9].

The only exclusion criterion was: patient not suitable for any treatment or refusing a diagnostic work-up.

The study was carried out according to the Helsinki criteria for clinical studies, and the participants could decide at any time to leave the study.

The data sheet contained 127 items subdivided as follows: 16 items regarded personal data, 13 clinical data, 15 imaging data, 22 characteristics of cystic lesion, 2 the final diagnosis, 3 surgery data, 3 related hereditary syndromes, 22 the drugs assumed by each patient and 31 the follow-up. The questionnaire requires about one hour to be completed. The study started on January $1^{\text {st }}, 2015$. The planned enrollment phase was two years from the ethical approval of any given center. The first follow-up evaluation was fixed at least two years after the last patient enrollment. The end of the follow-up was fixed for December 31st, 2021.

Of the 65 centers accepting to participate, 25 (38.5\%) enrolled patients, covering almost the entire national area. For the present interim analysis, the data regarding the epidemiological and clinical features and diagnostic workup were evaluated.

\subsection{Statistical analysis}

Data were presented as absolute numbers and their relative frequencies, and mean \pm standard deviation (SD). Statistical analysis was carried out using the analysis of variance (ANOVA) test, posthoc test using Bonferroni correction and the chi-squared test as appropriate. The data were run on IBM SPSS version 23.0 (IBM, Chicago, Illinois, USA). A significant difference was considered to having a $\mathrm{P}$ value of less than 0.05 . 


\section{Results}

The interim analysis was scheduled with the data available on December 31st, 2017. There were 1427 patients initially enrolled. Forty-two patients were excluded from the interim analysis due to incomplete data; 1385 were included in the analysis. Each of the 127 items was filled in over $90 \%$ of the cases.

\subsection{Patient characteristics}

All patients were enrolled at their initial imaging diagnosis of pancreatic cystic lesion suspected to be a CPN in 26 centers. The patients were enrolled from 12 university hospitals (46.2\%) and in 14 general hospitals (53.8\%). The recruitment came from 20 internist or gastroenterological units (76.9\%) and six surgical units (23.1\%. Of the 1385 patients mean age \pm SD $65.9 \pm 12.0$ years, range $18-92$ years), 510 were male (36.8\%) and 875 were female (63.2\%). The majority of patients were enrolled as outpatients (1220/1385, $88.1 \%$ ) and 165 (11.9\% were in-hospital patients. Fifteen of the 1385 patients $1.1 \%$ ) had no a CPN; diagnostic work up demonstrated that 14 had a pseudocyst due to chronic pancreatitis and 1 had a santorinicele.

The epidemiological characteristics of the patients enrolled according to type of cyst are reported in Tables 1 and 2 . The body mass index (BMI) in the study population was $24.9 \pm 4.1 \mathrm{~kg} / \mathrm{m}^{2}$, and according to the World Health Organization (WHO) criteria for BMI, [10] 41 (3.2\%) were underweight (BMI $\left.<18.5 \mathrm{~kg} / \mathrm{m}^{2}\right), 668(52.4 \%)$ were within the normal range (BMI $\left.18-5-24.99 \mathrm{~kg} / \mathrm{m}^{2}\right), 428(33.6 \%)$ were overweight (BMI $25-29.99 \mathrm{~kg} / \mathrm{m}^{2}$ ) and 138 patients $(10.8 \%)$ were obese $\left(\mathrm{BMI} \geq 30 \mathrm{~kg} / \mathrm{m}^{2}\right.$. Regarding the working activity data reported for 1384 individuals, classified according to the Italian Statistical National Institute [11], the study population was composed of 245 managers (17.7\%), 193 employees (13.9\%), 151 non-qualified professionals (10.9\%), 73 craftsmen (5.3\%), 87 intellectual professionals (6.3\%), 48 technical professionals (3.5\%), 74 businessmen (5.3\%), 6 military professionals $(0.4 \%), 3$ semi-qualified workmen $(0.2 \%)$ and 504 retired workers (36.4\%). Of the 504 retired workers, 44 had worked as managers, 108 (21.4\%) as employees, $145(28.8 \%)$ as non-qualified professionals, $77(15.3 \%)$ as craftsmen, $43(8.5 \%)$ as intellectual professionals, $34(6.7 \%)$ as technical professionals, $34(6.7 \%)$ as businessmen, $8(1.6 \%)$ as military professionals and 11 (2.2\%) as semi-qualified workmen. Taking into account alcohol and smoking habits, 367 (26.5\%) patients were smokers with a mean of $15.7 \pm 11.4$ (mean \pm SD) cigarettes per day (range 1-108), and 279 (20.1\%) patients drank alcohol, with a mean alcohol consumption of $20.3 \pm 24.3 \mathrm{~g}( \pm \mathrm{SD})$ (range $1-200$ grams) per day. Thirty-eight (13.8\%) and 230 (63\%) patients were former drinkers and smokers, respectively. Of the 1385 patients, 814 (58.8\%) were on at least one drug, in particular, 206 (14.9\%) took aspirin and 164 (11.8\%) statins.

Forty percent (518/1295) had a at least one 1 st degree relative affected by a solid tumor of the digestive and extra-digestive organs.

Regarding the clinical presentation, 338 of 1370 (24.7\%) had one or more symptoms/signs associated with a cystic lesion $(214,15.6 \%$, non-pancreatic abdominal pain; $106,7.7 \%$, acute pancreatitis; 12 , $0.9 \%$, diarrhea; $39,2.8 \%$, symptomatic gallstones; $21,1.5 \%$, weight loss; $9,0.7 \%$, fatigue; $2,0.1 \%$, appetite loss, $40,2.9 \%$, diabetes; 14 , $1.0 \%$, jaundice). However, the majority of the patients $(1036 ; 75.6 \%)$ were asymptomatic (Table 3).

\section{Diagnostic work-up}

As reported in Fig. 1, of the 2370 examinations (1.7 examinations per patient) which were carried out for diagnostic definition of cys-

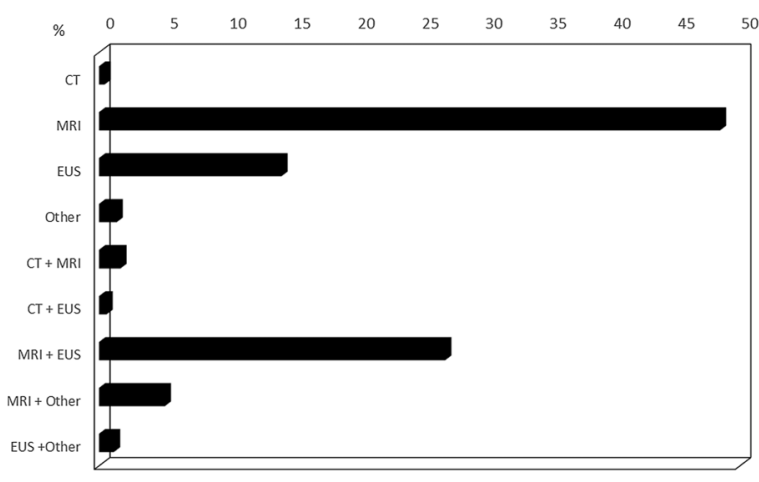

Fig. 1. Distribution of imaging techniques performed at diagnosis in the 1385 patients evaluated. The results are reported as percentages. CT: contrast-enhanced computed tomography; MRI: magnetic resonance imaging; EUS: endoscopic ultrasound, Other: positron emission tomography CT-PET or diagnostic endoscopic retrograde cholangiopancreatography ERCP.

tic lesions, magnetic resonance imaging (MRI) was performed as a single test in 671 (48.4\%) patients and in combination with EUS in 474 (27\%). Thus, EUS was the second most used test for diagnosing the cystic lesions (197 patients, $14.2 \%$ ). Computed tomography (CT) was carried out as single imaging examination in only 6 patients (0.4\%). Additional examinations, such as CT fluorodeoxyglucose (FDG) positron emission tomography (FDG PET-CT) in 36 patients, upper gastrointestinal endoscopy in 4 and endoscopic retrograde cholangiopancreatography (ERCP) in 6 were performed. There were no differences in the number of imaging examinations among the various types of cystic lesions $(\mathrm{P}=0.923)$. Tissue and/or fluid samples from the cystic lesions were obtained in 295 patients by EUS-FNA (fine needle aspiration) A self-limited mild acute pancreatitis was observed in 1 patient who underwent EUS interventional approach $(0.3 \%)$ that was treated conservatively. The cytology was diagnostic in 193 patients (65.4\%) and inconclusive in 102 patients (34.6\%). Intracystic levels of amylase and carcinoembryonic antigen (CEA) are reported in Table 4.

\subsection{CPN type and site}

Regarding the final diagnosis in the 1370 patients having CPNs, 1108 had an intraductal papillary mucinous neoplasm IPMN [960, $70.1 \%$, a branch-duct IPMN (BD-IPMN), 85, 6.2\%, a mixed type IPMN and 63, 4.6\%, a main duct IPMN (MD-IPMN)], 174 (12.7\%) had a serous cystadenoma, 38 (2.8\%) a mucinous cystadenoma, $21(1.5 \%)$ a non-functioning cystic neuroendocrine neoplasm (NEN), $9(0.7 \%)$ a solid-pseudopapillary cystic neoplasm, $4(0.3 \%)$ a cystic adenocarcinoma, and 16 (1.2\%) patients were defined as affected by an undetermined cystic neoplasm at the end of the diagnostic workup. The diagnosis was based on the combination of clinical, imaging and surveillance data in all patients, except for 78 (5.7\%) patients who were operated on after the initial workup. Seventy-six of the 78 patients $(97.4 \%)$ were operated in academic centers, 45 of them referred from non-surgical centers (57.7\%); the 30-days mortality was nil. The final diagnosis was mixed-IPMN in 24 patients (30.8\%), BD-IPMN in 20 (25.6\%), MD-IPMN in 9 (11.5\%), serous cystadenoma in 7 (9.0\%), mucinous cystadenoma in 6 (7.7\%), NEN in $6(7.7 \%)$, solid-pseudopapillary neoplasm in $5(6.4 \%)$, and 1 patient remained undiagnosed, even at pathologic examination (1.3\%). Thirty-nine patients had a distal pancreatectomy (50.0\%), 29 had pancreatic head resection (37.2\%), eight a total pancreatectomy (10.3\%) and 2 (2.6\%) an atypical resection (1.3\%\%). The remaining patients are still under active surveillance.

The location of the cystic lesions, reported in 1365 patients, was: the head of the pancreas in 526 patients 38.5\%), the body in 269 (19.7\%), the head and body in $137(10.0 \%)$, the tail in $126(9.2 \%)$, the 
Table 1

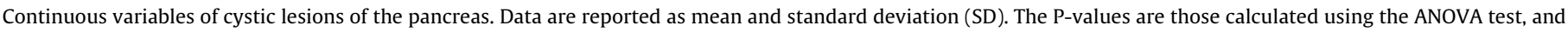
the P values vs. main duct IPMN are calculated by a post hoc test using the Bonferroni correction.

\begin{tabular}{|c|c|c|c|c|c|}
\hline Type of cystic lesion & Variable & No. of patients & Mean \pm SD & P value & P value vs. reference group \\
\hline MD-IPMN & \multirow{9}{*}{ Age at diagnosis } & 63 & $71.6 \pm 8.9$ & \multirow{9}{*}{$<0.0001$} & Reference group \\
\hline BD-IPMN & & 960 & $66.9 \pm 11.0$ & & 0.061 \\
\hline Mixed type IPMN & & 85 & $70.2 \pm 10.0$ & & 1 \\
\hline Serous cystadenoma & & 174 & $60.6 \pm 13.6$ & & $<0.0001$ \\
\hline Mucinous cystadenoma & & 38 & $57.3 \pm 17.1$ & & $<0.0001$ \\
\hline NEN & & 21 & $63.4 \pm 9.5$ & & 0.178 \\
\hline Solid-pseudopapillary neoplasm & & 9 & $47.1 \pm 18.8$ & & $<0.0001$ \\
\hline UCN & & 16 & $53.9 \pm 13.3$ & & $<0.0001$ \\
\hline Cystic adenocarcinoma & & 4 & $75.2 \pm 6.7$ & & 1.000 \\
\hline MD-IPMN & \multirow{9}{*}{ BMI $\left(\mathrm{kg} / \mathrm{m}^{2}\right)$} & 62 & $24.7 \pm 4.4$ & \multirow{9}{*}{0.826} & Reference group \\
\hline BD-IPMN & & 884 & $25.0 \pm 4.1$ & & 1.000 \\
\hline Mixed type IPMN & & 77 & $24.2 \pm 3.8$ & & 1.000 \\
\hline Serous cystadenoma & & 157 & $25.1 \pm 4.2$ & & 1.000 \\
\hline Mucinous cystadenoma & & 35 & $24.8 \pm 4.5$ & & 1.000 \\
\hline NEN & & 21 & $25.5 \pm 3.5$ & & 1.000 \\
\hline Solid-pseudopapillary neoplasm & & 8 & $23.9 \pm 4.5$ & & 1.000 \\
\hline UCN & & 12 & $25.3 \pm 4.8$ & & 1.000 \\
\hline Cystic adenocarcinoma & & 4 & $25.9 \pm 2.4$ & & 1.000 \\
\hline MD-IPMN & \multirow{9}{*}{$\begin{array}{l}\text { Largest size of main } \\
\text { cystic lesion (mm) }\end{array}$} & 59 & $18.1 \pm 13.9$ & \multirow{9}{*}{$<0.0001$} & Not included in the analysis \\
\hline BD-IPMN & & 928 & $17.1 \pm 12.1$ & & Reference group \\
\hline Mixed type IPMN & & 81 & $25.1 \pm 15.7$ & & 0.213 \\
\hline Serous cystadenoma & & 173 & $35.9 \pm 21.2$ & & $<0.0001$ \\
\hline Mucinous cystadenoma & & 37 & $40.9 \pm 25.5$ & & $<0.0001$ \\
\hline NEN & & 21 & $25.2 \pm 20.9$ & & 1.000 \\
\hline Solid-pseudopapillary neoplasm & & 7 & $62.3 \pm 42.5$ & & $<0.0001$ \\
\hline UCN & & 12 & $22.5 \pm 16.2$ & & 1.000 \\
\hline Cystic adenocarcinoma & & 4 & $21.3 \pm 7.4$ & & 1.000 \\
\hline MD-IPMN & \multirow{9}{*}{ Size MPD (mm) } & 59 & $6.9 \pm 4.6$ & \multirow{9}{*}{$<0.0001$} & Reference group \\
\hline BD-IPMN & & 938 & $2.9 \pm 2.5$ & & $<0.0001$ \\
\hline Mixed type IPMN & & 79 & $7.4 \pm 3.9$ & & 1.000 \\
\hline Serous cystadenoma & & 165 & $2.8 \pm 2.8$ & & $<0.0001$ \\
\hline Mucinous cystadenoma & & 34 & $2.4 \pm 0.6$ & & $<0.0001$ \\
\hline NEN & & 21 & $2.1 \pm 1.1$ & & $<0.0001$ \\
\hline Solid-pseudopapillary neoplasm & & 6 & $2.5 \pm 0.8$ & & 0.006 \\
\hline UCN & & 14 & $2.7 \pm 1.6$ & & $<0.0001$ \\
\hline Cystic adenocarcinoma & & 4 & $6.3 \pm 2.4$ & & 1.000 \\
\hline
\end{tabular}

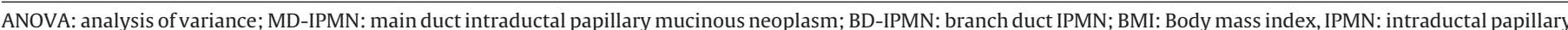
mucinous neoplasm, NEN: neuroendocrine neoplasm; MPD: main pancreatic duct. UCN: undetermined cystic neoplasm; ref: reference category.

head and tail in 42 (3.1\%), the body and tail in 109 (8.0\%), and diffuse throughout the gland in 156 (11.4\%). The size of the largest cystic lesion (mean \pm SD) was $21.3 \pm 16.9 \mathrm{~mm}$ and the largest diameter of the main pancreatic duct (mean $\pm \mathrm{SD}$ ) was $3.3 \pm 3.0 \mathrm{~mm}$.

\section{Clinical correlations}

The age of the patients, age at diagnosis, size of the cyst, and the size of the main pancreatic duct (Table 1 ) were statistically different within the various groups $(\mathrm{P}<0.001)$ whereas the BMI was not. The patients with serous cystadenoma, mucinous cystadenoma, solid-pseudopapillary neoplasm and an undetermined cystic neoplasm were statistically younger than the patients with MD-IPMNs (Table 1). The age of patients with BD-IPMN, serous cystadenoma, mucinous cystadenoma, solid-pseudopapillary neoplasm, and undetermined cystic neoplasm at diagnosis was statistically lower than that of the patients with MD-IPMNs (Table 2).

The size of the cystic lesion in patients with serous cystadenoma, mucinous cystadenoma and solid-pseudopapillary neoplasm was statistically greater than those with MDIPMN type 1 whereas the size of the main pancreatic duct was statistically greater in MD-IPMN, mixed-IPMN and cystic adenocarcinoma than in patients with BD-IPMN, serous cystadenoma, mucinous cystadenoma, neuroendocrine neoplasm, solid-pseudopapillary neoplasm and patients with undetermined cystic neoplasm (Table 1 ).

As reported in Tables 2 and 3, the symptoms before diagnosis were statistically different among the various types of cystic lesions.
Hereditary syndromes were present in 12 patients (9.0\%): in 10 associated with BD-IPMN (1.1\%), in 1 with MD-IPMN (1.6\%) and in 1 with serous cystadenoma $(0.6 \%)$; there were no differences regarding the frequency of hereditary syndrome among the various patients studied $(\mathrm{P}=0.981)$ (one for each of the following genetic diseases: hereditary ataxias, familial Alzheimer's disease, polycystic disease, Madelung's disease, prothrombin-related thrombophilia, MTHFR gene mutation, Von Hippel-Lindau disease, three for familial adenomatous polyposis, and three for BRCA mutation). None of these patients underwent surgery for a CPN.

The location of the CPNs was statistically different in the various CPNs as shown in Fig. 2.

The intracystic level of CEA was significantly different among the different types of cystic lesions $(P=0.020)$ whereas there was no significant difference in the intracystic concentration of amylase $(P=0.563)$. Finally, cyst size was not related to the intracystic CEA levels $(\mathrm{P}=0.134)$; this was also true taking into consideration only the 99 patients with BD-IPMNs in whom, there was no relationship between the diameter of the cyst and the intracystic CEA $(\mathrm{P}=0.160)$. Using $192 \mathrm{ng} / \mathrm{mL}$ of CEA as cut-off limit to differentiate mucinous ( $>192 \mathrm{ng} / \mathrm{mL})$ vs. no-mucinous cysts $(\leq 192 \mathrm{ng} / \mathrm{mL})$ [12], 38 of 113 (33.6\%) patients with mucinous cysts had levels of CEA greater than $192 \mathrm{ng} / \mathrm{mL}$, whereas 6 of 68 (8.8\%) with no-mucinous cysts had levels of CEA greater than $192 \mathrm{ng} / \mathrm{mL}$ and this difference was statistically significant $(\mathrm{P}<0.0001)$. Taking into consideration the communication of the cysts with the pancreatic ducts assessed by imaging studies, amylase levels were not statistically different ( $P=0.351$; amylase $23,190 \pm 59,942 \mathrm{U} / \mathrm{L}$ in communicating cysts vs. $13,163 \pm 66,585$ in no communicating cysts). 
Table 2

Distribution of categorical variables and their significance according to the various types of cystic lesions. The significantly different values are reported in bold.

\begin{tabular}{|c|c|c|c|c|c|c|c|c|c|c|c|c|c|c|c|c|c|c|c|c|c|}
\hline & & \multicolumn{2}{|c|}{ Gender } & \multicolumn{2}{|c|}{ Alcohol } & \multicolumn{2}{|c|}{ Smoking } & \multicolumn{2}{|c|}{ Fam Neo } & \multicolumn{2}{|c|}{ Symptoms } & \multicolumn{2}{|c|}{ Her Synd } & \multicolumn{2}{|l|}{ Drugs } & \multicolumn{2}{|l|}{ Aspirin } & \multicolumn{2}{|c|}{ Statins } & \multicolumn{2}{|c|}{ Panc. surgery } \\
\hline & & Male & Female & Yes & No & Yes & No & Yes & No & Yes & No & Yes & No & Yes & No & Yes & No & Yes & No & Yes & No \\
\hline \multirow{2}{*}{ MD-IPMN } & No. & 27 & 36 & 15 & 48 & 20 & 43 & 20 & 40 & 21 & 42 & 1 & 61 & 40 & 23 & 17 & 46 & 10 & 53 & 9 & 53 \\
\hline & $\%$ & 42.9 & 57.1 & 23.8 & 76.2 & 31.7 & 68.3 & 33.3 & 66.7 & 33.3 & 66.7 & 1.6 & 98.4 & 63.5 & 36.5 & 27.0 & 73.0 & 15.9 & 84.1 & 14.5 & 85.5 \\
\hline \multirow[t]{2}{*}{ BD-IPMN } & No. & 354 & 606 & 190 & 770 & 251 & 709 & 376 & 525 & 207 & 751 & 10 & 926 & 592 & 368 & 143 & 817 & 123 & 837 & 20 & 936 \\
\hline & $\%$ & 36.9 & 63.1 & 19.8 & 80.2 & 26.1 & 73.9 & 41.7 & 58.3 & 21.6 & 78.4 & 1.1 & 98.9 & 61.7 & 38.3 & 14.9 & 85.1 & 12.8 & 87.2 & 2.1 & 97.9 \\
\hline \multirow[t]{2}{*}{ M-IPMN } & No. & 39 & 46 & 24 & 61 & 26 & 59 & 26 & 52 & 36 & 49 & 0 & 83 & 52 & 33 & 15 & 70 & 13 & 72 & 24 & 61 \\
\hline & $\%$ & 45.9 & 54.1 & 28.2 & 71.8 & 30.6 & 69.4 & 33.3 & 66.7 & 42.4 & 57.6 & 0.0 & 100.0 & 61.2 & 38.8 & 17.6 & 82.4 & 15.3 & 84.7 & 28.2 & 71.8 \\
\hline \multirow[t]{2}{*}{ SCA } & No. & 56 & 118 & 36 & 138 & 48 & 126 & 63 & 99 & 34 & 138 & 1 & 168 & 87 & 87 & 17 & 157 & 7 & 167 & 7 & 167 \\
\hline & $\%$ & 32.2 & 67.8 & 20.7 & 79.3 & 27.6 & 72.4 & 38.9 & 61.1 & 19.8 & 80.2 & 0.6 & 99.4 & 50.0 & 50.0 & 9.8 & 90.2 & 4.0 & 96.0 & 4.0 & 96.0 \\
\hline \multirow[t]{2}{*}{ MCA } & No. & 6 & 32 & 5 & 33 & 7 & 31 & 14 & 21 & 13 & 25 & 0 & 37 & 13 & 25 & 4 & 34 & 1 & 37 & 6 & 32 \\
\hline & $\%$ & 15.8 & 84.2 & 13.2 & 86.8 & 18.4 & 81.6 & 40 & 60 & 34.2 & 65.8 & 0.0 & 100.0 & 34.2 & 65.8 & 10.5 & 89.5 & 2.6 & 97.4 & 15.8 & 84.2 \\
\hline \multirow[t]{2}{*}{ NEN } & No. & 9 & 12 & 0 & 21 & 3 & 18 & 3 & 18 & 6 & 15 & 0 & 21 & 5 & 16 & 1 & 20 & 1 & 20 & 6 & 15 \\
\hline & $\%$ & 42.9 & 57.1 & 0.0 & 100.0 & 14.3 & 85.7 & 14.3 & 85.7 & 28.6 & 71.4 & 0.0 & 100.0 & 23.8 & 76.2 & 4.8 & 95.2 & 4.8 & 95.2 & 28.6 & 71.4 \\
\hline \multirow[t]{2}{*}{ PPN } & No. & 3 & 6 & 0 & 9 & 1 & 8 & 3 & 5 & 6 & 3 & 0 & 8 & 4 & 5 & 0 & 9 & 1 & 8 & 5 & 4 \\
\hline & $\%$ & 33.3 & 66.7 & 0.0 & 100.0 & 11.1 & 88.9 & 37.5 & 62.5 & 66.7 & 33.3 & 0.0 & 100.0 & 44.4 & 55.6 & 0.0 & 100.0 & 11.1 & 88.9 & 55.6 & 44.4 \\
\hline \multirow[t]{2}{*}{ UCN } & No. & 6 & 10 & 4 & 12 & 4 & 12 & 5 & 6 & 5 & 11 & 0 & 14 & 9 & 7 & 4 & 12 & 4 & 12 & 1 & 13 \\
\hline & $\%$ & 37.5 & 62.5 & 25.0 & 75.0 & 25.0 & 75.0 & 45.5 & 54.5 & 31.3 & 68.8 & 0.0 & 100.0 & 56.3 & 43.8 & 25.0 & 75.0 & 25.0 & 75.0 & 7.1 & 92.9 \\
\hline \multirow[t]{2}{*}{ CAC } & No. & 1 & 3 & 1 & 3 & 2 & 2 & 2 & 2 & 2 & 2 & 0 & 4 & 3 & 1 & 1 & 3 & 0 & 4 & 0 & 4 \\
\hline & $\%$ & 25.0 & 75.0 & 25.0 & 75.0 & 50.0 & 50.0 & 50.0 & 50.0 & 50.0 & 50.0 & 0.0 & 100.0 & 75.0 & 25.0 & 25.0 & 75.0 & 0.0 & 100.0 & 0.0 & 100.0 \\
\hline$P$ value & & 0.098 & & 0.107 & & 0.545 & & 0.274 & & $<0.001$ & & 0.968 & & $<0.001$ & & $<0.001$ & & 0.009 & & $<0.001$ & \\
\hline
\end{tabular}

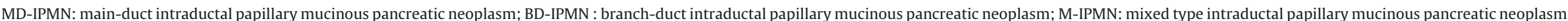

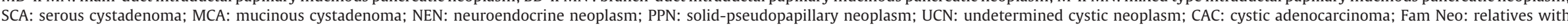
neoplasia; Her Synd: association with hereditary syndromes; drugs: pharmacological treatment; Panc. surgery: pancreatic surgery. 
Table 3

Main symptoms and signs at diagnosis and statistical significance according to the various types of cystic lesions. The significantly different values are reported in bold.

\begin{tabular}{|c|c|c|c|c|c|c|c|c|c|c|c|}
\hline & \multicolumn{11}{|c|}{ Symptoms/signs at diagnosis } \\
\hline & & No. & $\mathrm{aAP}$ & Ac Panc & Diarrhea & Bil & WL & Fatigue & $\mathrm{AL}$ & DM & Jaun \\
\hline \multirow[t]{2}{*}{ MD-IPMN } & No. & & 10 & 3 & 1 & 1 & 2 & 1 & 0 & 5 & 2 \\
\hline & $\%$ & & 15.9 & 4.8 & 1.6 & 1.6 & 3.2 & 1.6 & 0.0 & 7.9 & 3.2 \\
\hline \multirow[t]{2}{*}{ BD-IPMN } & No. & & 143 & 64 & 8 & 28 & 13 & 6 & 1 & 29 & 8 \\
\hline & $\%$ & & 15.1 & 6.8 & 0.8 & 3.0 & 1.4 & 0.6 & 0.1 & 3.1 & 0.8 \\
\hline \multirow[t]{2}{*}{ Mixed type IPMN } & No. & & 13 & 17 & 0 & 5 & 2 & 0 & 0 & 2 & 3 \\
\hline & $\%$ & & 15.3 & 20.0 & 0.0 & 5.9 & 2.4 & 0.0 & 0.0 & 2.4 & 3.5 \\
\hline \multirow[t]{2}{*}{ SCA } & No. & & 26 & 10 & 2 & 2 & 2 & 2 & 1 & 1 & 0 \\
\hline & $\%$ & & 15.3 & 5.9 & 1.2 & 1.2 & 1.2 & 1.2 & 0.6 & 0.6 & 0 \\
\hline \multirow[t]{2}{*}{ MCA } & No. & & 12 & 2 & 0 & 2 & 1 & 0 & 0 & 0 & 0 \\
\hline & $\%$ & & 31.6 & 5.3 & 0.0 & 5.3 & 2.6 & 0.0 & 0.0 & 0.0 & 0.0 \\
\hline \multirow[t]{2}{*}{ NEN } & No. & & 1 & 5 & 0 & 1 & 0 & 0 & 0 & 1 & 0 \\
\hline & $\%$ & & 4.8 & 23.8 & 0.0 & 4.8 & 0.0 & 0.0 & 0.0 & 4.8 & 0.0 \\
\hline \multirow[t]{2}{*}{ PPN } & No. & & 3 & 0 & 0 & 0 & 0 & 0 & 0 & 1 & 0 \\
\hline & $\%$ & & 42.9 & 0.0 & 0.0 & 0.0 & 0.0 & 0.0 & 0.0 & 14.3 & 0.0 \\
\hline \multirow{2}{*}{ UCN } & No. & & 3 & 1 & 1 & 0 & 1 & 0 & 0 & 0 & 0 \\
\hline & $\%$ & & 20.0 & 6.7 & 6.7 & 0.0 & 6.7 & 0.0 & 0.0 & 0.0 & 0.0 \\
\hline \multirow[t]{2}{*}{ CAC } & No. & & 0 & 0 & 0 & 0 & 0 & 0 & 0 & 1 & 1 \\
\hline & $\%$ & & 0.0 & 0.0 & 0.0 & 0.0 & 0.0 & 0.0 & 0.0 & 25.0 & 25.0 \\
\hline
\end{tabular}

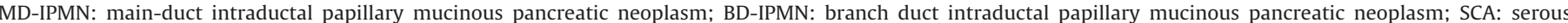

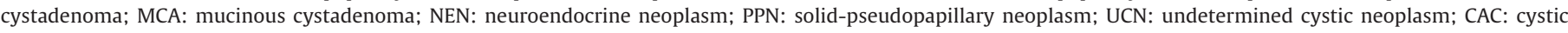

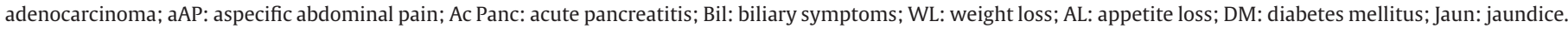

Table 4

Intracystic concentrations of amylase and CEA according to the different CPNs. Data are reported as mean, standard deviation (SD) and range.

\begin{tabular}{|c|c|c|c|c|c|}
\hline & & No. & Mean \pm SD & Range & P value \\
\hline \multirow[t]{9}{*}{ CEA (ng/mL) } & MD-IPMN & 4 & $279.1 \pm 326.0$ & $0.5-624.8$ & \multirow{9}{*}{0.020} \\
\hline & BD-IPMN & 99 & $3,249.0 \pm 13,669.1$ & $0.2-91,000$ & \\
\hline & Mixed-type IPMN & 3 & $4,602.5 \pm 5713.6$ & $7.6-11,000$ & \\
\hline & SCA & 52 & $153.8 \pm 726.1$ & $0-4360$ & \\
\hline & MCA & 7 & $108.6 \pm 198.9$ & $0-549$ & \\
\hline & NEN & 10 & $2.5 \pm 1.18$ & $1.1-4.1$ & \\
\hline & PPN & 1 & 0.5 & $0.5-0.5$ & \\
\hline & UCN & 3 & $355.2 \pm 613.8$ & $0.7-1064$ & \\
\hline & CAC & 1 & 44,000 & 44,000 & \\
\hline \multirow[t]{9}{*}{ Amylase (IU/L) } & MD-IPMN & 2 & $114,614.0 \pm 161,381.6$ & $500-22,8728$ & \multirow{9}{*}{0.563} \\
\hline & BD-IPMN & 73 & $21,564.0 \pm 56,805.0$ & $0-280,000$ & \\
\hline & Mixed-type IPMN & 3 & $1795.7 \pm 1879.7$ & $123.1-3,830$ & \\
\hline & SCA & 42 & $14,635.7 \pm 79,413.2$ & $1-507,500$ & \\
\hline & MCA & 6 & $7059.2 \pm 17,117.6$ & $11-42,000$ & \\
\hline & NEN & 9 & $20.3 \pm 12.9$ & $10-46$ & \\
\hline & PPN & 1 & 156 & 156 & \\
\hline & UCN & 3 & $46,029.3 \pm 50,415.9$ & $146-100,000$ & \\
\hline & CAC & 0 & & & \\
\hline
\end{tabular}

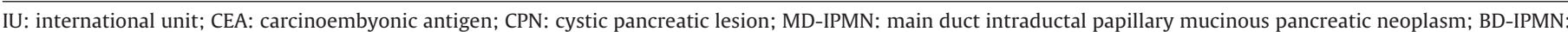

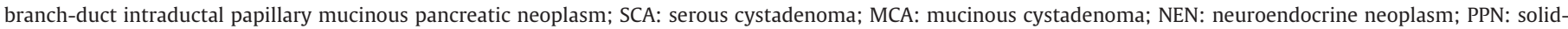
pseudopapillary neoplasm; UCN: undetermined cystic neoplasm; CAC: cystic adenocarcinoma.

No significant differences among the types of colonic lesions were seen at colonoscopy in patients with the various types of cystic lesions $(P=0.129)$.

\section{Discussion}

In the clinical arena, the characterization and management of CPNs pose a substantial dilemma since there is a significant overlap in the morphology of benign and premalignant lesions. There are also few data obtained from large prospective series regarding CPNs, and no information on the optimal management exists despite the many inherent guidelines available at present [5].

The strengths of the present survey are represented by its large size, prospective design and countrywide data collection, allowing a sound analysis, and a reliable portrait of the epidemiology, clinical data, characteristics and diagnostic workup of CPNs in a real-life setting. The online sheet requiring one-hour for each patient to be completed may be one of the reasons why of the 65 centers that initially accepted to participate only 38.5\% enrolled patients. In addition no economical support for any given patient enrolled was expected.

The epidemiological data resulting from this survey either confirm previous data or add some new insights.

Regarding the epidemiological characteristics of the population enrolled, $63.4 \%$ of the patients were found to be female; no significant differences were found among the various types of cystic lesions which was is in agreement with the current literature [13].

There were no differences among the various cystic lesions regarding alcohol intake and smoking habit that were similar to those of the Italian population [14] as well as regarding familiarity for neoplasia, and association with hereditary syndromes whereas significant differences were found for the use of drugs, aspirin and statins; this latter figure is also in agreement with Italian studies regarding IPMNs [13]. The percentage of overweight and obese patients was similar to that of the general Italian population [14]. The BMI was also similar among the various types of cystic lesions, whereas age of patients and age at diagnosis were significantly dif- 


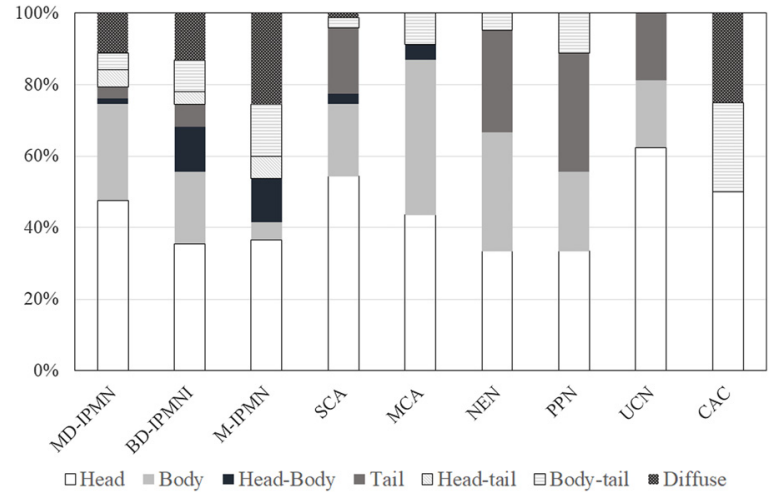

Fig. 2. Localization of the CPNs along the pancreatic gland. The localization is significantly different $(\mathrm{P}<0.001)$. MD-IPMN: main-.duct intraductal papillary mucinous pancreatic neoplasm; BD-IPMN: branch-duct intraductal papillary mucinous pancreatic neoplasm; M-IPMN: mixed-type intraductal papillary mucinous pancreatic neoplasm; SCA: serous cystadenoma; MCA: Mucinous cystadenoma; NEN: Neuroendocrine neoplasms; PPN: solid-pseudopapillary neoplasm; UCN: undetermined cystic neoplasm; CAC: cystic adenocarcinoma.

ferent among the different types of lesions. Finally, the size of the largest cystic lesion was greater in patients with serous, mucinous cystic lesions and those with pseudopapillary neoplasms whereas the size of the main pancreatic duct was, as expected, greater in patients with MD-IPMN and BD-IPMN, and in those with cystic adenocarcinoma.

Regarding the clinical presentation, $75.8 \%$ of the patients enrolled were asymptomatic and this figure is similar to that reported in previous studies [15-18]. The location of the cystic lesions was in the head of the pancreas in more than $50 \%$ of cases.

From a diagnostic point of view, we used the cut-off of $192 \mathrm{ng} / \mathrm{mL}$ to differentiate mucinous from no-mucinous cysts as suggested by Brugge et al. [12] and we found that about onethird of patients with mucinous cyst had levels of CEA greater than $192 \mathrm{ng} / \mathrm{mL}$. At present, CEA in pancreatic cysts is considered the most accurate tumor marker for diagnosing mucinous cysts [4]; several studies have been published with variable ranges of CEA levels for the optimal detection of mucinous cysts ranging from $30 \mathrm{ng} / \mathrm{mL}$ to $480 \mathrm{ng} / \mathrm{mL}$ [19-22]. In a single center experience, cyst fluid CEA was evaluated in 154 subjects to differentiate mucinous from non-mucinous cysts [23] one third of the patients did not have enough fluid for CEA analysis; as in our cases, a significant difference was seen between mucinous, serous, and inflammatory cyst types [23]. However, in the near future we need more reliable intracystic markers to differentiate mucinous from non-mucinous cystic lesions such as genetic panel analysis.

Considering the communication of the cysts with the pancreatic ducts assessed by imaging studies, amylase levels were not statistically different from cyst communicating with pancreatic tree and those did not. Why this happens is not clear, but it is possible that amylase may be present at elevated concentrations also in no-communicating cysts as may happen in inflammatory cysts [24].

In the absence of an associated solid component, pancreatic cyst fluid from mucinous cysts is frequently acellular or has low cellularity with a resultant low diagnostic yield; thus, the data in the present study agreed with those previously published showing that, although the cytologic findings were highly specific, they were insensitive [23]. Finally, the diameter of the cyst did not seem to be a marker of malignant transformation.

Thus, as suggested by Italian guidelines we need more sensitive biochemical tests in the near future to guide the management of patients with pancreatic cysts and a comprehensive test, such as for example the Compcyst based on selected clinical features, imaging characteristics, and cyst fluid genetic and biochemical markers may become an alternative to CEA determination [25].

Regarding the use of imaging techniques for the diagnosis of cystic pancreatic lesions, all patients underwent MRI with or without pancreatography, or multidetector computed tomography with pancreatic protocol. Endoscopic ultrasound was carried out to identify patients with an uncertain radiological diagnosis, once again in line with the recommendations of the Italian guidelines [5,6]. Endoscopic ultrasound was the only modality to obtain a sampling of both the content and the wall of the cystic lesions. The frequent use of EUS-FNA is not due to a selection bias but instead reflects the large nationwide diffusion of this tool. The pathological cytology was diagnostic in $65 \%$ of the cases, in line with previous literature.

None of the patients with hereditary syndrome underwent surgery, contrary to the recommendation of the Italian guidelines that a family history of pancreatic cancer represents an indication for resection. From a clinical point of view, it should be pointed out that some of the hereditary forms were not pancreatic, and there was no relationship with the size of the cyst in these patients; however, this aspect should be clarified in a dedicated study.

Surgery was carried out on the majority MD-IPMN and mixed type IPMN patients, and in patients with cystic neuroendocrine neoplasms, but less frequently in patients with solid pseudopapillary neoplasms. These data were surprising, and the follow-up of these patients will probably clarify why patients with solid pseudopapillary neoplasms were operated on in a percentage lower than that of other cystic lesions of the pancreas. Finally, 97.4\% patients were operated in high volume academic centers and this may explain the lack of 30-days postoperative mortality accordingly to previous published national surgical survey data [26].

\section{Conflict of interest}

None declared.

\section{Acknowledgements}

The Gioja Bianca Costanza Fund supported the Research Fellowship of G. Belfiori

\section{References}

[1] Farrell JJ. Prevalence, diagnosis and management of pancreatic cystic neoplasms: current status and future directions. Gut Liver 2015;9:571-89.

[2] Pezzilli R. Asymptomatic lesions of the pancreas: an overview. J Gastroenterol Hepat Res 2014;3:1216-9.

[3] Zerboni G, Signoretti M, Crippa S, Falconi M, Arcidiacono PG, Capurso G. Systematic review and meta-analysis: prevalence of incidentally detected pancreatic cystic lesions in asymptomatic individuals. Pancreatology 2019;19:2-9.

[4] AGREE II instrument update: September 2013.

[5] Buscarini E, Pezzilli R, Cannizzaro R, De Angelis C, Gion M, Morana G, et al. Italian consensus guidelines for the diagnostic work-up and follow-up of cystic pancreatic neoplasms. Dig Liver Dis 2014;46:479-93.

[6] Falconi M, Crippa S, Chari S, Conlon K, Kim SW, Levy P, et al. Quality assessment of the guidelines on cystic neoplasms of the pancreas. Pancreatology 2015:15:463-9.

[7] Cahalane AM, Purcell YM, Lavelle LP, McEvoy SH, Ryan ER, O'Toole E, et al. Which is the best current guideline for the diagnosis and management of cystic pancreatic neoplasms? An appraisal using evidence-based practice methods. Eur Radiol 2016;26:3121-8.

[8] Early DS, Acosta RD, Chandrasekhara V, Chathadi KV, Decker GA, Evans JA, et al. Adverse events associated with EUS and EUS with FNA. Gastrointest Endosc 2013;77:839-43.

[9] Banks PA, Bollen TL, Dervenis C, Gooszen HG, Johnson CD, Sarr MG, et al. Classification of acute pancreatitis 2012: revision of the Atlanta classification and definitions by international consensus. Gut 2013;62:102-11.

[10] WHO. Obesity: preventing and managing the global epidemic. Geneva, Switzerland: WHO technical report series 894; 2000.

[11] Istituto Nazionale di Statistica (ISTAT). Nomenclatura e classificazione delle unità professionali., Rome, Italy. Istat.it professioni.istat.it/ sistemainformativoprofessioni/cp2011/index.php. [2011, accessed 12 November 2018]. 
[12] Brugge WR, Lewandrowski K, Lee-Lewandrowski E, Centeno BA, Szydlo T, Regan $S$, et al. Diagnosis of pancreatic cystic neoplasms: a report of the cooperative pancreatic cyst study. Gastroenterology 2004;126:1330-6.

[13] Capurso G, Boccia S, Salvia R, Del Chiaro M, Frulloni L, Arcidiacono PG, et al. Risk factors for intraductal papillary mucinous neoplasm (IPMN) of the pancreas: a multicentre case-control study. Am J Gastroenterol 2013;108:1003-9.

[14] Istituto Superiore di Sanità. Salute in Italia e livelli di tutela: approfondimenti dalle indagini ISTAT sulla salute. Roma, Italia Rapporti ISTISAN 16/26; 2016.

[15] Zanini N, Giordano M, Smerieri E, Cipolla d'Abruzzo G, Guidi M, Pazzaglini G, et al. Estimation of the prevalence of asymptomatic pancreatic cysts in the population of San Marino. Pancreatology 2015;15:417-22.

[16] Jais B, Rebours V, Malleo G, Salvia R, Fontana M, Maggino L, et al. Serous cystic neoplasm of the pancreas: a multinational study of 2622 patients under the auspices of the International Association of Pancreatology and European Pancreatic Club (European Study Group on Cystic Tumors of the Pancreas). Gut 2016;65:305-12

[17] Pezzilli R, Calculli L. Branch-type intraductal papillary mucinous neoplasm of the pancreas: clinically and patient-reported outcomes. Pancreas 2015;44:221-6.

[18] Kulzer M, Singhi AD, Furlan A, Heller MT, Katabathina VS, Mcgrath KM, et al. Current concepts in molecular genetics and management guidelines for pancreatic cystic neoplasms: an essential update for radiologists. Abdom Radiol (NY) 2018;43:2351-68.
[19] Snozek CL, Mascarenhas RC, O'Kane DJ. Use of cyst fluid CEA, CA19-9, and amylase for evaluation of pancreatic lesions. Clin Biochem 2009;42:1585-8.

[20] Khalid A, Zahid M, Finkelstein SD, LeBlanc JK, Kaushik N, Ahmad N, et al. Pancreatic cyst fluid DNA analysis in evaluating pancreatic cysts: a report of the PANDA study. Gastrointest Endosc 2009;69:1095-102.

[21] Leung KK, Ross WA, Evans D, Fleming J, Lin E, Tamm EP, et al. Pancreatic cystic neoplasm: the role of cyst morphology, cyst fluid analysis, and expectant management. Ann Surg Oncol 2009;16:2818-24.

[22] Linder JD, Geenen JE, Catalano MF. Cyst fluid analysis obtained by EUS-guided FNA in the evaluation of discrete cystic neoplasms of the pancreas: a prospective single-center experience. Gastrointest Endosc 2006;64:697-702.

[23] Cizginer S, Turner BG, Bilge AR, Karaca C, Pitman MB, Brugge WR. Cyst fluid carcinoembryonic antigen is an accurate diagnostic marker of pancreatic mucinous cysts. Pancreas 2011;40:1024-8.

[24] Oh HC, Kang H, Brugge WR. Cyst fluid amylase and CEA levels in the differential diagnosis of pancreatic cysts: a single-center experience with histologically proven cysts. Dig Dis Sci 2014;59:3111-6.

[25] Springer S, Masica DL, Dal Molin M, Douville C, Thoburn CJ, Afsari B, et al. A multimodality test to guide the management of patients with a pancreatic cyst. Sci Transl 2019;11:501.

[26] Balzano G, Capretti G, Callea G, Cantù E, Carle F, Pezzilli R. Overuse of surgery in patients with pancreatic cancer. A nationwide analysis in Italy. HPB (Oxford) 2016;18:470-8. 